\title{
VERNACULAR VIDEO ANALYSIS - COMMUNICATIVE CONSTRUCTION OF EVIDENCE IN POLICE WORK
}

\author{
RENÉ TUMA ${ }^{1}$ \\ ${ }^{1}$ Technical University of Berlin, Department of Sociology, Fraunhoferstraße 33-36, Room FH 914, 10587 \\ Berlin, Germany. ORCID: 0000-0001-9672-1694, Email: rene.tuma@tu-berlin.de
}

\begin{abstract}
The use of video recordings for the production of knowledge has spread all over society. This paper presents an empirical study of the processes of interpretation of audio-visual recordings. It draws on an example in the context of police work, including the investigation of recordings of police violence. With a theoretical background in communicative constructivism, special attention is given to situated bodily forms of "making things visible" performed by the participants. Interpretation is not understood as purely cognitive but rather as a communicative process. It is elaborated on presenting results of (reflexive) videography of practices of video-interpretation. However, the specifics of the work are not only brought upon situatively, but are embedded in an institutional and organizational context. This paper draws on the concept of work arcs, that allow to highlight the trans-situative linkage.

KEYWORDS: Vernacular Video Analysis, Visual Knowledge, Police Work, Communicative Action
\end{abstract}

\section{VERNACULAR VIDEO ANALYSIS ${ }^{1}$}

During the linguistic turn in the 1960s and 1970 the focus was especially on language, the Iconic Turn followed in the 1990s and 1990 and added the question of what role visual communication plays and whether the "visual" must be interpreted in a special way. ${ }^{2}$ Against this background, my research addresses the latter questions, but does

\footnotetext{
${ }^{1}$ The study presented here is part of a wider study on video analytical practices published in Tuma (2017).

${ }^{2}$ The specific role of the visual material, compared to language is extensively discussed in a variety of disciplines and a seperate field of visual studies has developed. One of the key texts can be found by W.J.T. Mitchell (2002), who maps out some of the main issues. Also in sociology the visual has been discussed extensively, here I focus on the aspect of visual knowledge (cf. Lucht, Schmidt, and Tuma 2013).
} 
not provide a mere methodological or abstract "pictorial-philosophical" approach, but embeds those topics into a framework of sociological-empirical or communicative-constructivism. This research approach has been developed on the basis of social constructivism (Berger and Luckmann 1966), presenting an enhanced concept of communicative action and especially taking objectivities (this means also technologies etc.) into consideration (cf. Knoblauch in this issue 2019a; Knoblauch 2019b). Following this concept, which starts with analyzing "fist order constructions" (Schutz 1962) I do address the questions as a participant or ethno ${ }^{3}$-problem and investigate how those are dealt with. The practices of "seeing" and importantly "showing" are central to sociality. Knoblauch (2019b) discusses this in detail on the basic example of finger pointing, partly with reference to Tomasello (2010). A very specific, technologically enhanced form of seeing and showing, which is currently becoming more and more present, is the use of video in everyday working contexts. It became increasingly clear to me that the medium "video", which many sociologists themselves use to explore interactions (Knoblauch, Schnettler, and Tuma 2014), is not exclusive to our profession, but is constantly used by various practitioners in their respective fields. Soci ety observes itself, much more "concretely" than expressed with Luhmanns abstract concept of observation (1997). Therefore, during the early stages of my research, looked for experts in video analysis and found them nearly everywhere: From market researchers, sports coaches, police officers to doctors, communication trainers, etc. In all those fields analysts scrutinize videos with varying intensity and frequency: from time to time as part of other activates or even as a full-time job. I therefore describe the dissemination of the systematic evaluation of video data in various social fields with the term Vernacular Video Analysis. "Vernacular" in its original meaning aims at the language spoken in local contexts and/or by specific groups, but has already been transferred by the pioneer of pictorial gymnastics, W.J.T. Mitchell, to the forms of everyday seeing that art historians have ignored (as "vernacular seeing" - Mitchell 2005: 365). I have chosen this term for the paraphrase of the research object because it encompasses three important aspects of vernacular video analysis:

- the specificity for the respective application context,

the 'pragmatic' functionality and

the everydayness.

I use the term Vernacular Video Analysis to describe a certain group of practices, namely the systematic evaluation of videos in the respective professional everyday life (There are similar uses of the concept, e.g. Mair et al. Smith 2018 and with a slightly different connotation Schmidt and Wiesse 2019). The actions they consist of are not purely situational, but are specifically embedded into specific domains, which I refer to as 'fields'. I am focusing, firstly, on the analyses of videos in which the ac tors have specifically produced or at least collected the video data in the context of their professional activities in order to evaluate which analysis refer to the 'actions in front of the camera' (see Reichertz and Englert 2011: 28). Watching a film, be it on the couch in the evening or in a film analysis seminar, does not fall within my

\footnotetext{
In the sense of ethnomethodology.
}

scope, because participants here do not interpret the 'natural' actions of people in front of the camera ${ }^{4}$, but rather follow the crafted programme for entertainment. In such cases, where produced video is in focus of research, we would therefore usually speak of film analysis rather than video analysis. Secondly, it is an activity in which the video is used to produce knowledge. While this is certainly embedded in broader contexts of action, in an analysing or interpreting activity the focus is on the interpretation of the video material, rather than on its processing and production. This allows some further forms of the use of video to be distinguished, such as the production of live television footage in sports (Perry, Juhlin, and Engström 2014) or the editing and production of films (Laurier, Strebel, and Brown 2008). These activities also include aspects of the analysis activity, but do not aim at gaining knowledge, but at the film or the transmission as a product. Thirdly, video analysis, as understood here, must be distinguished from surveillance activities, in which CCTV systems are used to keep a live eye on rooms outside of the field of vision, where the boundaries are fluid. These use of video technology, which is often also embedded in coordination tasks, e.g. in control centres, have already been investigated by the Workplace Studies (Heath and Luff 2000; Heath et al. 2002; Luff, Heath, and Svensson 2008). Those differ because the video technology is used there in a similar way to "binoculars" or "periscopes" and not as a "time machine". From my broader research, which includes video analyses in sports coaching and market research (cf. Tuma 2017), the following will examine the communicative construction of interpretation with several using the examples of the analyses by the police and their "counterparts".

\section{EMPIRICAL EXAMPLE: VIDEO ANALYSIS IN POLICE WORK}

Video footage is mainly used in police work in the following areas: firstly, by the traffic police for the detection of traffic offences; secondly, in the investigation of criminal offences, in particular when recordings from surveillance cameras are available; thirdly, in the area of operational law enforcement, e.g. in the targeted observation of organised crime; and lastly, in the observation and surveillance of major events (e.g. football, demonstrations). After a brief look at the history of video recording and a short review of the literature, I will turn empirically to the latter case.

Since around 1960, video cameras have played a role in the form of permanently installed surveillance systems. Video technology, which was initially used for traffic monitoring, was used early on to monitor crowds. As early as 1960, cameras borrowed from the entertainment company EMI were used to observe onlookers visiting the Thai royal family in London's Trafalgar Square (Fay 1998; Kammerer 2008a: 35; 2008b). In Germany, cameras with recording functions were used sporadically as early as the early 1960s at the demonstrations on May, the first, in Hanover and at other events in Frankfurt and Munich (Kammerer 2008a: 48). From the 1970s onwards, in addition to use of traffic surveillance by the police, there was also a massive increase in privately

The camera's actions, which represent the institutionalized view of a professional group (see Reichertz and Englert 2011: 28-30), also play a role in some cases, but are not the focus of attention; rather, they are dealt with in the context of "problems". 
operated video surveillance systems owned by retailers. In the beginning, they were mainly used for real-time monitoring, but in the following years, they were increasingly equipped with recording devices. ${ }^{5}$ Particularly with regard to demonstrations and major events, the targeted use of video recording in Germany was legally regulated in 1989 with the amendment or introduction of the ban on the wearing of masks (\$§ 12a, 19a Versammlungsgesetz). In recent years, the use of video recording has increased due to the availability of everyday, affordable and robust video equipment. In addition to legal issues, current discussions are increasingly revolving around the use of camera drones, which can also film from the air, without the need for expensive helicopters (see also Ullrich and Wollinger 2011), and the permanent use of individual body cams. Usually, for example, crowd and riot control units of police forces, have their own teams for the preservation of evidence and documentation, and are supported by technical support teams. They are equipped with video cameras, live transmission facilities and additional tools. ${ }^{6}$

In addition to evaluating research, the use of video by law enforcement agencies today is mostly negotiated within the framework of surveillance studies, which primarily deal with questions concerning the effect of surveillance technologies. The central and frequently cited reference and starting point of the research are mostly Foucault's studies on panoptism (1977), based on the control potential of new technologies, especially in an urban context. The further development of these reflections about the consequences and power effects of surveillance, led to a discourse that produced its own journals and a whole series of anthologies and introductory volumes (Ball, Haggerty, and Lyon 2014; Hempel and Metelmann 2005; Lyon 2007; Zurawski 2007). In this area, questions are usually negotiated concerning the dissemination, acceptance and enforcement of surveillance technologies; their involvement in the generation of suspicious facts and the normalisation and classification of populations; and the consequences and power effects of surveillance, especially with regard to exclusion and discrimination processes. Rarely do the studies in this area focus on surveillance

${ }^{5}$ As Zielinski (2010) shows, the technological development of film and video equipment is also oriented towards surveillance purposes at an early stage, so that, in terms of innovation theory, at least a co-evolution must be assumed here, in which the new practices are not only a consequence of the technology, but were specifically designed to implement certain control visions.

${ }^{6}$ These supra-regional units, which are closely coordinated with operation planning, are often also equipped with special documentation vehicles with extendable mast cameras and several workstations, which are used in large-scale situations where criminal offences are expected from a crowd of people (stone throwing, etc.). According to practical literature, these vehicles are equipped with recording equipment, editing suites, Internet connection and printers (Timmermanns in Polizeispiegel, Dec. 2010). The application scenario is described as opportunity to print out short sequences from the video or still pictures ("for better recognizability with an image processing program edited") already durin events, which are filmed by the roof camera or by an official with a hand camera. These will then be to the emergency officers, so that they can appearance with these 'profiles' and seize them ("by means of burdock tactics" op. cit. means: individual offenders are deliberately pulled out of crowds by small troops). In the usage vision, the video sequence is also "edited simultaneously with a video editing program (e.g. by inserting circles or arrows) in order to make the accused better recognizable" practices in detail. Perhaps because of the partial overemphasis of the new technologies (technology determinism), possibly because of problems with access to the field or because of the orientation towards a theoretical, abstract perspective. Although there are some exceptions, such as the studies on CCTV (Closed Circuit Television) surveillance in Great Britain in the 1990s (Norris and Armstrong 1999). As is usual in the field of Surveillance Studies, these also deal with permanent CCTV surveillance, which is less about systematic evaluation and analysis of individual cases but about permanent monitoring with punitive consequences.

The practices that are at my research focus, happen when recordings are precisely analysed, i.e. the analysist seeks traces of action (also see Ginzburg 2011; Krämer, Kogge,and Grube 2007; Reichertz 2007). This is often referred to as part of video forensics. Digital video forensics, however, highlight the improvement of the recording, such as the improvement of the image quality or the acquisition of data from various technical video systems (analogue, digital, tape, server, etc.). Alternatively, the term often refers to the purely technical analysis of physical, technical or biological processes using video, such as the reconstruction of a trajectory of a grenade or a drone bomb (cf. Weizmann et al. 2014). Video forensics has rarely been the subject of sociological research so far. Gates does pioneering work here with an STS perspective (Gates 2013 $244)$. She shows how images are produced, data is archived, and the data processed for presentation in court or in other settings, as part of the subsequent evaluation of criminal cases. In particular, it focuses on the digital transformation of images using video and image processing software, i.e. the production of evidence from a "chaotic field" of recordings and finally describes the result as "computational objectivity" in accordance with the concepts of Daston and Gallison (2010). Daston and Gallison use scientific illustrations to illustrate how the "notion of objectivity" changes historically. Extended to videos, the term emphasizes not only the application of algorithms for image optimization, but also the management of large data archives (Gates 2013: 248 ), on the basis of which videos can only act as evidence. The work of the video forensic experts is to make decisions about which visual information to focus on and which can be ignored. Gates' perspective is very enlightening, but it neglects the communicative character of these activities. After all, this is not just a solitary activity, but rather the result of ongoing communication between different participantsm also the negotiation of relevancies and standards (cf. also Reichertz 2009).

This becomes clear, considering the work by Charles Goodwin on Professional Vision (1994), which has meanwhile become a classic of ethnomethodological video analysis. His study is based on the first Rodney King trial. It deals with ${ }^{7}$ racist acts of

\footnotetext{
The role of the moving image in court at Schwartz (2009), which traces the judicial use of film and video in the last hundred years, is depicted more broadly historically. He first describes the introduction of the first film footage, which for a long time could not gain a foothold in court, but was merely viewed by witnesses who then reported on it. Films, at least in the USA of the 1940s and 1950s, were occasionally framed as physical evidence or as pictorial communication of witness statements. It was only with the introduction of the smaller handheld video devices that the moving image found its way into the courtrooms, always accompanied by intense arguments about the status of the recordings a evidence in comparison to other types of evidence. In the 1980s, lawyers considered videos to be the
} 
violence committed by police officers during the arrest of a car driver in Los Angeles in the 1990s, which were filmed by passers-by. Together with Major Harness Goodwin, he emphasizes (Goodwin and Goodwin 1997) that the discursive-practical aspects of seeing and showing can thus explain how in the first trial, the video could be presented and interpreted by the defence attorneys, with a certain interpretation scheme of the policemen, as evidence for the justified use of violence, against the 'rebelling' Rodney King. Not, as initially expected, as a clear documentation of an 'excess of police violence' against a person lying on the ground. Goodwin shows the communicative process in which the video could be interpreted in court by the defence counsel, with the help of a series of small practices (such as breaking it down into short segments, emphasizing certain aspects, prescribing an "Escalation - De-escalation" coding scheme for the police professional view).

Even if this is a solid starting point, there are massive sociological gaps in research on the concrete use of videos and their analysis in police work itself (i.e. before it goes to court; even practitioner's literature is thin on the ground and is often passed on as grey literature in training courses. The little empirical research that deals with the analysis of videos in the context of police work, therefore bears subtitles such as "an orphaned field of research" (Ullirich and Wollinger 2011b) and deals primarily with questions of the effect of the camera on demonstrations. Suggestions for the specificity of police investigative work, can be drawn from the broader literature on police research, which, however, usually deals with 'broader' aspects of police culture (Behr 2006) and also frequently takes a historical approach (Wilson 2000). In the context of this work, however, more relevant are studies on police work presented by some researchers, in particular the research group 'Empirical Police Research' (Ute Donk, Ronald Kurt, Jo Reichertz, Norbert Schröer), which deal specifically with investigative activities. Practices such as the examination of witnesses and the recording of records at the crime scene come into focus (Reichertz 2003; Schröer 1996: 199). Reichertz has dealt intensively with the criminal police's search for traces within the framework of a six-month ethnography (Reichertz 1991; 1996). He describes trace reading as an active construction activity:

And also another fact should be clear now: traces are not simply read (...), but they are constructed. The forensic man's gaze examines all perceptible phenomena at the scene of the crime and only with the help of a pronounced imagination does he enchant some of these phenomena into traces. The metaphor that often appears, according to which traces conceal a secret message that could be deciphered with the right key, is fundamentally misleading. (1991: 18)

Even if the video data did not yet play a role in his research, or at least are not explicitly negotiated and emerged (video devices already existed at the end of the 1980s), this perspective represents a good starting point in the context of this work to look at

most reliable form of evidence (p. 106) until their evidence character became fragile again as a result of cases such as that around Rodney King (whose outcome Schwartz tries to explain with the difference between subjective and subjectless seeing). Today, videos are used in court, but they have lost their sole claim to objectivity and are now only accepted embedded in a comprehensive chain of evidence. video analysis with the police. Since Reichertz dealt with the criminal investigation department in particular with cases in which the events were 'completely unclear' to the officers, there are, of course, a number of differences in identifying perpetrators at demonstrations and proving the facts on the basis of video recordings of the events. Since video does not provide clear or even an unambiguous image of a situation, but only a document of the event that can be questioned and interpreted in different ways, the course must also be constructed as a trace and transformed into evidence.

\section{EMPIRICAL: ANALYSIS OF VIDEOS IN POLICE WORK}

This paper presents part of a comparative study, where I compared practices of vernac ular video analysis in three fields: market research, sport training (football) and police work (Tuma 2017). The research design and applied methods follow the concept of videography, that combines ethnographic research with in-details sequential analysis of relevant sequences ${ }^{8}$ as it is presented in our introduction to the method (Knoblauch et al. 2014). The research question is focused on how the visual practices of different fields are related to their contextual specifics. For this case, I have studied the context empirically and then focused on concrete analysis of video data in police work. The aim was to observe the analysts, while they are working with video data. In this case, I focus on video analyses of violence in the context of major events and demonstrations, as the use of the video camera in such cases was a regular and systematized practice. However, the degree of professionalism and intensity is strongly dependent on specific local conditions. For example, in the context of larger investigations or media-effective events such as the events on New Year's Eve 2015 in Cologne, special video analysis units are gathered, as there are broad alternative information resources here due to the great public interest.

In concrete research practice, field access proved to be quite difficult, since sociologists do not have (any longer) an easy access, nor a permission to film the "backstage" of investigative work. Nevertheless, through interviews, exemplary demonstrations of the procedure and comparison with other sources, I was able to develop an understanding of the forms of video analysis in criminal investigation work. ${ }^{9}$ In the follow-

${ }^{8}$ The specific selected sequences are choosed based on extensive theoretical and comparative sampling within the field and the data corpus (cf. Knoblauch et al. 2014:71f). My research shows the widely spread communicative communicative forms, but also embedds them in specific situated context. The empirical research is based on data from 2010-2014, however the general practices have not changed, new technologies such as better video quality, new forms of recording (body cams, drones) are not dramatically changing the work practices. Currently automatized forms of computer based video analysis (facial recognition) etc. are beeing deployed, but do not replace the need to interpret the visual results, but rather help speeding up parts of the work process (scanning large sources of data, focussing attention). I have discussed the concepts in the broader study (Tuma 2017: 151ff)

'It is therefore not ethnography in a broader sense that claims to document "police culture" or the like, but my research is clearly focused on the forms of analysis. The comparison with other research fields with similar activities was helpful. This study is based on ethnographic research in the different fields, whereas prolonged stays in the context of police was not possible. The specific case is based on three interviews with experts in a local police unit in a german metropolitan city, the documentation of a 
ing discussion I will trace the path of the video footage, from the recording in use to the analysis and production of evidence. I also refer to this process as work ark (Gerson 1983 in reference to Strauss). ${ }^{10}$

\section{THE RECORDING OF THE VIDEOS BY THE POLICE}

An important reason for the use of video technology by police units in the field, results from the necessity to fix the identification features of perpetrators. The aim is to make the identities communicatively accessible to other members of the police and juridical institution. The image or description of the perpetrators must be enabled to be passed on, which would be a complicated task if performed only in words. Therefore, visual methods of identification and preservation of evidence are used (criminal photography has a long history, as a look at criminal historians shows, cf. Messner 2013; Messner, Gruber, and Musik 2012; Tagg 1988). On one hand, this identification has the aim of being transferred to other members of the crowd and riot control units during the action; on the other, the records are subsequently evaluated, archived and later brought into the court hearing as visual evidence and therefore, as part of the respective case file.

My interviewees have ${ }^{11}$ reported the recording procedure as a problematic task, as it is accompanied by concrete practical issues of filming and by legal demands at the same time. As a rule, the documentation teams are confronted with confusing situations in the field. They usually don't know beforehand where the 'trouble spots' will be, are in motion in 'mobile locations', are often confronted with multitude of 'disturbers', who have developed countermeasures to 'being filmed' (so called "black block", exchange of clothes, banners in front of the body, obfuscation by fireworks, etc.), they have to struggle with poor visibility conditions and usually have to film during movement. For this reason, the camera operators in the units receive specific training to prepare them for dealing with such tactical problems. In the area of major events, the basic approach is not to document the entire event, but to record the most serious individual acts in as much detail as possible. At the same time, however, overview shots are also produced, from which an overview of the situation and the mood of the event is to emerge.

The use of the video camera by the police (here in relation to demonstrations and meetings in public space) is formally and legally strongly regulated in Germany, where my study took place. ${ }^{12}$ The observance and breaking of these rules is again and again

demonstration of video analytic work and because of the limited access also the in detail analysis of the contrast case based on one hour conference recording (which I also attended). However, this specific case is part of a larger set of data and analysis, for which months in the two other research fields, over 50 hours of video recordings and twelve expert interviews as well are the empirical basis.

${ }^{10}$ The work sheet is a counter term to the trajectory that Strauss used above all to emerge from external compulsion. In contrast, the work arc emphasises the active production of a project by various expert groups (cf. Strübing 2005: 213).

Interview with a second police director of a big city and two "video experts" from police units.

${ }^{12}$ It is regulated above all by §12a of the Assembly Act (VersG). However, the abstract rules must be the subject of legal disputes. This is crucial for the police units, because they cannot simply record the ongoing action without providing a specific reason. Recording of citizens is a justifiable violation of the fundamental rights of the recorded. Police officers are therefore under constant pressure to justify their actions, as they may have to justify why the event was filmed. Thus, the recording may only begin when a crime (for example a stone is thrown) has already taken place. Especially with such very short actions, it can be assumed that the camera cannot capture any criminal activity during the course of the action, or execution, because the first steps are already over when the recording button is pressed. However, it usually does not stop at a single crime, so the camera can be switched on from the first event so that the images can then be used to identify the perpetrators. Also persons who are standing by (who could possibly commit the later act) may then be recorded. Tactically, it makes sense for the police to be able to start filming as early as possible in order to obtain the best possible footage of the following events for the comprehensive technical preservation of evidence. In the training documents, documentation-relevant events are listed which should ideally be recorded:

The officers of the evidence corps are making technical evidence about the: - predicate phase

- perpetration

- perpetrators and accomplices

- arrest including search of the person and his or her property (however, the search of persons may only be filmed for the purpose of securing evidence, but not for the purpose of proving the legality of the exercise of official authority)

- means of committing an offence (if possible, save the original)

- consequences (injuries, damages)

They shall immediately produce immediate photographic material about the arrested person, as well as further photographic material about the objects that can serve as evidence. The instant picture is handed over to the arresting officer, who accompanies the arrested person to the station. The footage is attached to the 'Report on Deprivation of liberty/restriction' and given a sticker number.

(Anonymous 2004: Police Workbook Tactics [at Demonstrations])

This list is based on an ideal-typical action progression model, which starts from individual perpetrators (and accomplices) and followed by concrete, observable actions, which can already be taped in action. Such process models conceive these actions in such a way that they have a "predicate offence phase" and can (usually) already be recognised or at least expected there, when the perpetrators carry out preparatory actions. In fact, certain means are used that have relevance as evidence (thus, a distinction is also made between different types of evidence, such as fact based evidence, personal evidence, etc.).

interpreted. I cannot and will not judge what this practice is because I have not researched it. 
The preservation of evidence serves not only as a 'subjective' understanding of the deed, but is also intended to document, prove and make visible to third parties, certain forms of action that have already been classified as relevant. As already mentioned, the aim of the documentation teams is to produce recordings, which serve for arrest and detention and, in the further course of proceedings, for the unequivocal proof of the acts of any suspects. The gaze of the police - which assumes a constant threat situation - is already produced by means of the camera actions (cf. for the term: Reichertz and Englert 2011). The accusation is to be made plausible and presentable in its course, the perpetrator identifiable. The documentation teams themselves also attach importance to the accompanying spoken commentary by the filming police officers, which is also recorded - and is intended to simplify the later evaluation, since the relevant settings are recorded. The police officers on duty usually describe the observed in an already "coding" and police typical tone of voice that is intended to be 'factual' and objective, therefore somewhat choppy. This recorded sound on the camera, which was recorded during the event, not only serves the practical purpose of highlighting and explaining what was shown, but also contributes to a "Liveness" preserved in the video (Auslander 1999). There is some awareness that the video can also have an emotional effect. It also reflects on whether the viewers are aware of the perspective and whether any video is to be doubted, because it often happens that accusations of selectivity or manipulation are made against the video. Therefore, they attach great importance to handling the video data in such a way that these doubts do not arise in the first place and accusations are invalidated. The video material thus does not speak for itself, but only as a process-legitimated document. The video recordings are archived on a hard disk server, where they should be kept in the original file structure of the camera, log data sheets should be filled in as already in use, the time codes of the camera should be checked (which often leads to problems, e.g. if the batteries were empty), etc. This means that the video production anticipates its later use as evidence and there are procedures in place to ensure the legitimacy of the recordings, for example by excluding subsequent alteration or editing by individual officials.

\section{SUBSEQUENT RECONSTRUCTION OF A 'RIOT'}

Documentation is a routine activity embedded in the execution of action in the field first, perpetrators are identified and, if possible, arrested; second, evidence for prosecution is documented by means of the videos. The evaluation of the recordings serves the protocol-like representation of the events, to which often stills, sometimes also recorded material are attached. This requires a selection of the sequences from the body of recordings. The file consists of a standardised presentation of the course of the criminal act with the necessary information such as place, time, means of committing an offence, etc., which is passed on to the subsequent case handler and then used in court. This handling of the video material on which the documentation is based usually only becomes more apparent in more complicated cases. I was told about an event as an example of a case, where the police could not arrest the 'perpetrators' directly on the spot, but tried to find them afterwards, via video recordings. This is a major event with political explosiveness, at which the police units initially only had the task of securing the site and therefore did not expect further police-relevant incidents. On the basis of a small dispute, however, the situation escalated and the police units were attacked and stones and other objects were thrown at them. Due to various circumstances, the perpetrators could not be detained on the spot and therefore only the video material produced at the time could be used for criminal prosecution. For this reason, a special commission (SoKo) was formed, as the head of the police authority told me:

$\mathrm{K}$ : And, uh, a special commission sat over it for a relatively long time, viewed, uh, hundreds of hours of video footage and related sequences again and again. We have also added records of parking surveillance cams that have given an completely different perspective? Those and surveillance cameras from the nearby tram stop, which is actually there to make sure that no one jumps around in the track when the tram arrives, you know? Things like that. But the recordings are also available to us in such a case and then all this will be put together ... (Interview with a police director in May 2013)

Large quantities of video materials had to be evaluated. First, hundreds of hours had to be viewed, sorted, processed and made accessible. This activity is carried out by trained personnel - although in this case the training was initially referred to as "television studio work". This term refers to the initial technical component of this activity, which consists in bringing the available video data into a uniform format, organising it, providing it with titles and making it easily accessible. According to my interview partners, these activities could in principle be done by any "technically competent" personnel with knowledge of a common video editing software and few other tools, but there are some limitations that are discussed below.

First, I turn to the methods and settings of analysis. The process of video analysis forms an overarching work arc embedded in the general police activities, which contains the selection, the classifying interpretation of the offence and its preliminary course, the identification of perpetrators, the collection and consolidation of evidence as well as the comprehensive presentation with the help of the video material. It also includes the production of meaningful still images and a standardised description of the course of crime, with necessary information such as place, time, means used, etc. The results are then passed on to the case worker responsible and used later in court, when the case is brought to trial. The underlying methods of action for the evaluation are particularly evident in more complex cases.

When asked to what extent this knowledge of the analysts require a specific pool of police experience, the statements of the interviewed experts are to a certain extent ambivalent. Parts of the 'technical' activity are apparently perceived by some officials as simple, monotonous and under-demanding, while others, seeking traces and interpreting, were perceived as very demanding and interesting. Above all, however, the interpretations with consequences have a high degree of responsibility, so that the decision as to whether or not a crime has been committed can only be taken by trained police officers. On one hand my interview partners agree on this, the appro- 
priate training is necessary for legal security. On the other hand, reference is made to the daily experience of policemen and women who have worked on the street in many years of training and work. Various anecdotes and reports of their special intuition are presented in interviews to prove this aspect. My interviewees also emphasize that the evaluation is typically not carried out by one person alone, but is itself a communicative process between several people working on the material, in which the observations are mutually checked and supplemented. The processing of the cases is also organized according to the division of labour: the sequences are cut out, documented, provided with screenshots, progress and location descriptions and then handed over to the case worker who initially had nothing to do with the actual video evaluation. The case worker is then responsible for bringing charges, prosecuting the perpetrators and initiating legal proceedings.

From the previous remarks it becomes clearer, how the pure identification and classification activity becomes a social and communicative constructivion of evidence. ${ }^{15}$ The officials select a series of typified actions and place them in a mental context that can be described as a "trace". Reichertz summarizes this on the basis of his research on forensics: "Objects do not become traces by themselves, this statement shows, but only on the basis of intellectual work which juggles with far-reaching assumptions and insinuations" (Reichertz 1996: 15). However, the trace is not simply read, but in terpreted together and communicatively in this way 'created' from various individual observations, which do not necessarily have to be completely and continuously visible on a videotape alone, but which move across various places (videotapes that record the course of time; photos on which faces are recognizable; other clues or testimonies) must be 'assembled' into a meaningful and in this case convincing, process in a communicative counter- and togetherness. At this point the reference to special police knowledge becomes clear again: the practitioners and theorists of the field themselves emphasize that specific investigator qualities are necessary for this: "The discovery of traces is largely dependent on the inner attitude, the resourcefulness and the power of observation of the searching officials" (cf. Clages and Steinke 2002; cited after Reichertz 1996). It must be emphasized that the reflexive documentation of the procedure is already built into this activity, since the officials are aware that the described trace only has a convincing evidential effect as when in an interaction with other data.

In the presentation of the results, the videos are not the primary means used, but the files also contain still images, photos and process descriptions, as explained in the example above. All these materials can be understood as material representations, as Goodwin (1994) described them. They serve as evidence by picking out key images from the action that clearly focus on specific visible movements (we see an example below), i.e. function as objectified pointing and, in conjunction with the documenting descriptions of the crime, reduce the process to central key moments and selected courses of action. Only then the relevant actions are displayed, i.e. made visible.

\footnotetext{
${ }^{13}$ This phenomenon could also be described with the concept of "circulating reference" (Latour 1999).
}

CONTRAST CASE COUNTER ANALYSIS: COMMUNICATIVE CONSTRUCTION OF

\section{EVIDENCE OR POLICE VIOLENCE AGAINST A CYCLIST}

At this point I change the perspective for the reasons of access to data, already mentioned above, but remain with records of major events. Nowadays, video analysis for evidence purposes, is not only carried out by the police, but also in a variety of contexts (football, shopping centres, malls, etc.). Even if there are other actors in a different context, they act in a very similar way to police. For they development of a narration (similar to a trace to follow) on the basis of 'chaotic recordings', which they put together on the basis of the various videos.

For this kind of data analysis, I have video recordings of the presentation of the results that are to be used in order to be able to represent the performatively physical side of the interpretation activity.

On this "other side", video is used to prove police violence. It is well known that allegations are often made that acts of violence were part of police strategy or carried out by individual officers, often causing a great deal of public attention. One can speak here of a counter analysis or counter monitoring (Ullrich and Wollinger 2011a; Wilson and Serisier 2010). If these cases are also considered, it becomes clear that the same video data can be used to interpret different circumstances and that there are different possibilities for interpretation. The point here is to direct the video cameras and today in particular the ubiquitous smartphone cameras of the demonstrators towards the police units in action, in order to document unjustified and/or excessive use of force and missteps; and later make them accessible to the public.

A particularly clear case of such counter-analysis was presented at a conference of a German hacker group. At a demonstration a few months earlier, a person "the cyclist in the blue T-shirt" had been attacked and injured by a number of police officers after he had inquired about the service number of one of the officers on duty. This case of police violence against a cyclist was widely discussed at a number of Interne forums and by a hacker's club, immediately after the event. A number of participants and interested activists had collected videos of the event, documented from different perspectives, in order to enable a reconstruction of the event and its prehistory. These videos caused a great public response and a press response: there was a statement by the Berlin police, who first gave a disregarded reprimand as justification for the action and finally announced a criminal case against two police officers "for bodily injury in office". At the conference, a detailed analysis of the events of the respective day was presented, on the basis of various recordings, in particular the main event, namely the police assault, was examined in detail with the help of the video. Police records created by documentation teams were also used. These were accessible, because they were part of the case file, to which the concerned parties and their lawyers had access. For the purpose of the exact evaluation of the events, the presenters had different videos cut together: The video, on the basis of which the evidence is communicatively constructed, has a special characteristic: it is not just a recording, but a time-synchronized compilation (a fourfold split screen) that produces a kaleidoscope-like diversity of perspectives (see the first video image below in Fragment D2). The individual shots 
stand side by side as 'visual witnesses' of the event and synchronously show the same event from different angles. It should be noted that the individual cameras in the video are mostly in quite fast motion, which leads to great irritation when viewing. The video only becomes comprehensible over time, after repeated viewing and focusing on individual sections.

This multi-perspective representation is interesting because, on one hand, it represents an objectified form of compiling and interrelating different documents, a procedure which is also used by police officers in a similar form to produce evidence. This cut shows when the expressiveness of an individual video is questioned and often it does not seem to function as pure evidence itself. No perspective can show the whole of the ongoing action and the shots are blurred in different places or the perspective hides parts of the event. The presenters trust in the persuasiveness of this multi-perspectivity, which exceeds that of an original video - and also that of the police cam eras. They create a new vision with the help of technology and also communicatively. Combined with the commentary, they make the video "speak" convincingly. The claims to validity are, at least this is how it is presented, higher in this case than in other forms of evidence. Already, through the specific video construction, in which a certain assumption is inscribed, the speakers show the point of view by multiplying it in such a way that their interpretation has a higher visibility and thus also a higher validity. This creates a more convincing representation than just a single shot. Other modalities of evidence, such as sound stored with the recordings (which are neglected in the analysis) or testimonies, are not used in this context. This evidence seems to be objectified within the video compilation, which itself produces the impression of overview and thus neutrality through its multi-perspectivity, which a single video is unable to achieve due to its solo-perspectivity.

However, even in this case the video does not stand alone. It will be presented in detail in the above-mentioned presentation; two speakers will first explain a series of background information and previous events on stage and then present their video analysis. So, they show what they see in the video. The video is not simply played but interpreted by commentary. The two speakers on stage (here anonymously called Joscha and Otto) have obviously prepared the material and reproduce their acquired knowledge in front of an audience of about $200 .{ }^{14}$ The analysis is thus a communicative construction in the double sense (Keller, Knoblauch and Reichertz 2013). On one hand, they reconstruct the action on a screen; on the other hand, they also demonstrate how one (and thus the audience is addressed) can read it, from the traces visible in the video. The speakers are thus faced with the communicative problem of developing a convincing interpretation from the blurred images, or more precisely: of making their own, pre-prepared construction of events understandable and convincingly comprehensible, by means of the video image projected onto the wall. They have to make the audience "see". To this end, they apply a series of "small performative forms

${ }^{14}$ It is also a lecture that "reconstructs" an analysis and not an analysis itself. This has to be taken into account, but these data "satisfy" the requirements to be able to deduce the approach of the analysis activity. of visualization", which can be regarded as typical for video interpretations:

- use the video as a pointing tool (pause, enlarge, split screen)

pointing with hand or pointer, speaking, gesticulating, posture, body, drawing on a video image

- development of a narrative, naming, typification of actors

The video image or also: the remote control of the "video recorder" itself, is used as a pointing instrument when, as becomes clearer below in the transcript, it is stopped exactly one moment before something happens or while something becomes visible. The very fine control of the display (forwards, backwards, faster, slower) by means of digital video technology allows Otto, synchronously and precisely coordinated with his or Joscha's statements, to lead the image to a still image in which individual persons can be shown and identified. The video device is therefore not only used for re-playing the recording, but rather for isolating and highlighting moments, individual elements and is used deictically.

A short example should illustrate this. The presentation begins in the tenth minute of the presentation on the police assault. Since a short recording of the concrete unjustified police violence against a peaceful demonstrator to be proven, it is assumed to be already known to the spectators in the hall because the topic was already widely circulated in the corresponding political 'scene' in advance. The edited recordings here serve, on one hand, for the already discussed expansion of perspectives, on the other hand, the more exact reconstruction of the relevant events, directly before the act of violence. Otto has just explained how the data comes about and controls the video presentation from his notebook on the lectern in front of him. Joscha is currently at the edge of the action and watches. The video now shows several people (in this case only on one camera, top left of the picture; the rest is black, except for the timecode) running through the camera image. Otto already stops the video image after a few seconds when a person to be identified as a policeman steps into the middle of the image. With some additional remarks, he identifies a certain policeman, as an important offender, who is to be observed in the later course of the video. It is interesting to note that the visual instructions also refer to the non-verbal forms of communication (glances, turns and turns), which are later to be read as part of a command structure and as evidence for action planning. 


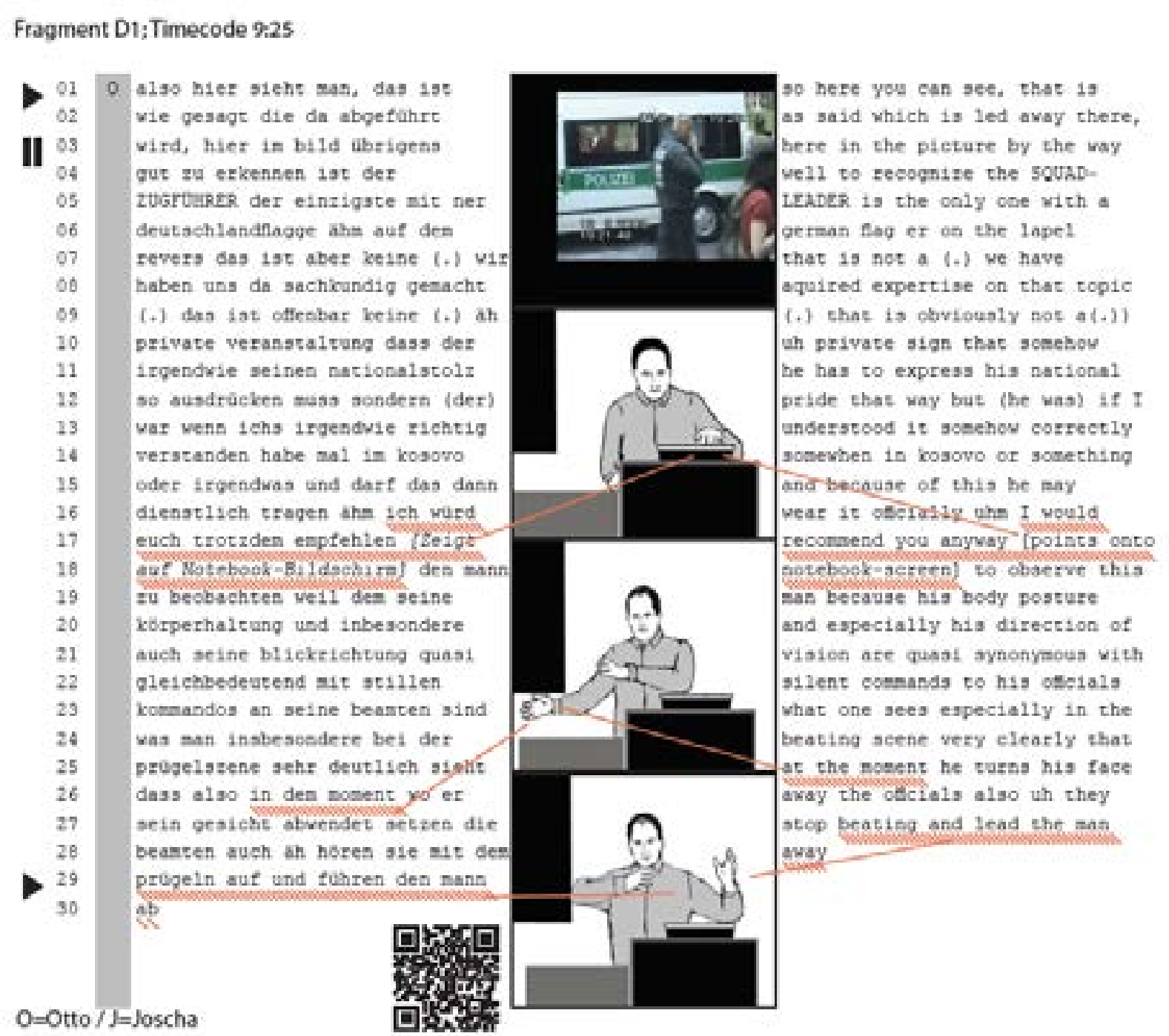

By means of his communicative actions, Otto thus gives visual instructions in advance for the analysis, which are intended to permit the comprehension of a more complex event. The video is then played further and Joscha explains once again the synchronous cut and the relevance of the timecode. The video is continued until, according to Otto, it comes to a "not quite insignificant scene". At this point Otto stops the video again and begins to explain the situation, whereupon Joscha steps in and points to individual actors within the video (fragment D2).

\section{Fragment D2; Timecode 14:15}

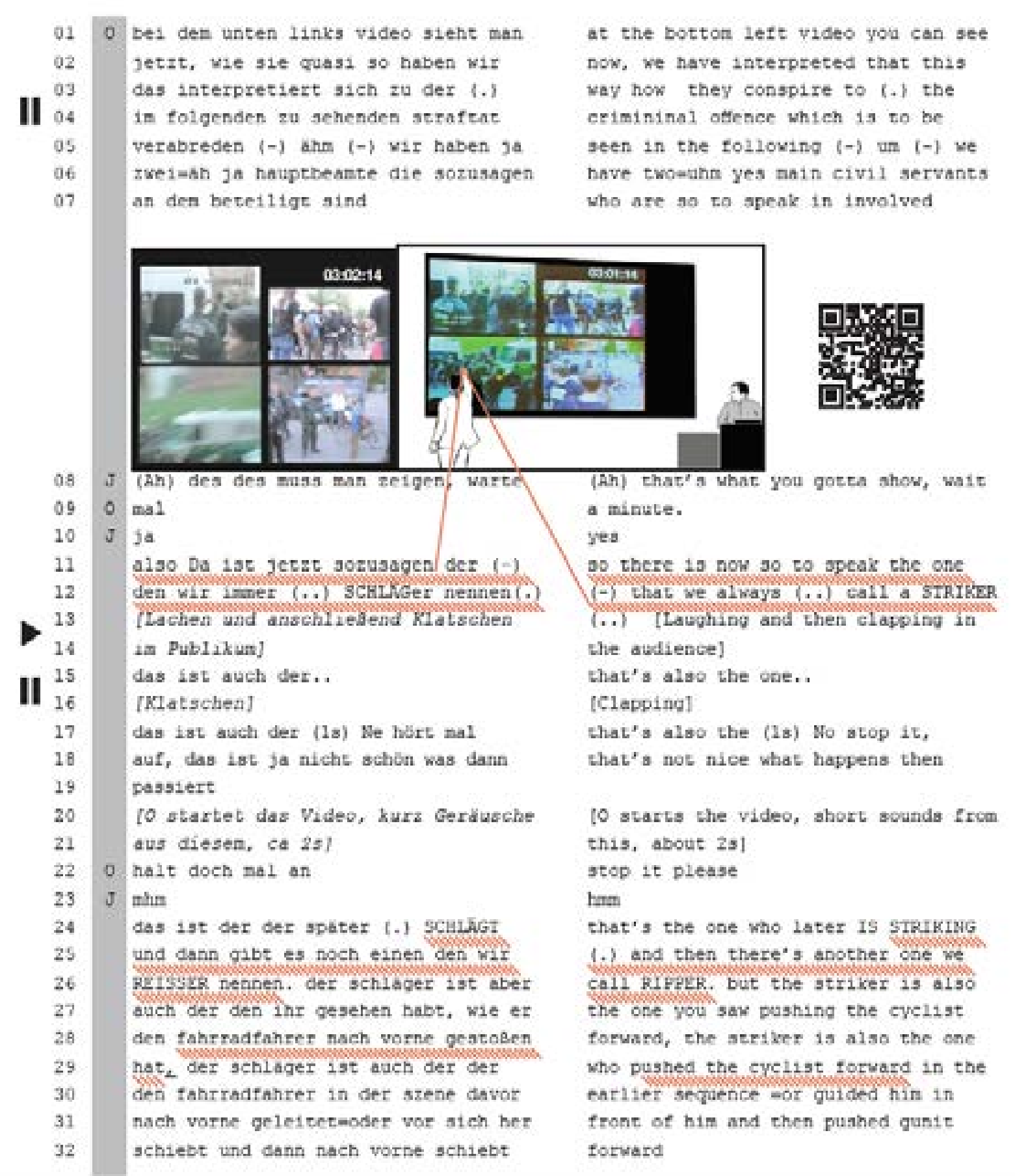

This fragment shows that Joscha clarifies the observations by pointing into the video, using his body as a hinge to connect the video images thrown onto the wall with the typification of the actors (cf. also Knoblauch on showing, 2008). He first points to the canvas (fragment D1 line 8-9) and turns his gaze to the audience. The highlighting of a person is turned into irony by the exaggerated depiction of a policemen as a "thug". It is acknowledged as understood by the audience with a clap and laughter. This reaction is to be understood as a communicative action of the audience - which shows that in this case, too, the presenters and the audience create something to- 
gether and communicatively - namely the shared interpretation of the video sequence shown.

This passage in the video is of central importance, as the typification of individuals develops a narrative that is brought together from a series of attributions of roles, such as the perpetrator and the victim in a systematic description of the execution of the act of violence. The action cannot yet be seen, but the typifications in the picture are preparing the audience through the direction of the gaze. According to that, viewers pay attention to specific details and share the same interpretation relevance. Previously shown sequences are put into context by the speakers (lines 18-23) and thus interwoven into an interpretation as a planned crime (lines 3-4).

Not only the pure emphasis of individual actors plays a role, but in particular the physical displacement and comprehension of relevant movements in space. As already written above, it is difficult for the audience without prior knowledge to recognize anything on screen. Also, the description of the individual persons on the basis of verbal representations is problematic, due to the their uniforms. However, distinctive body movements are easy to recognize, which can be used to identify the relevan ones. At the same time, the movements are related to the situation in which the video was recorded. This becomes particularly clear (in this case) in the relevant spatial organization during the event (in front; behind the policemen; areas that can be entered by demonstrators and those that are guarded by the police; etc.). It is very difficult for viewers to comprehend these aspects based on the moving cameras, without precise local knowledge. Joscha's "Re-Enactment" offers a solution to this problem (for the term see below). Joscha plays the reconstructed event in the space created on stage, taking on the role of the perpetrators, re-enacting typical movements of the policeman, such as pushing and escorting (underlined in lines 21 - 23) - and thereby manages, through his body orientation, to define the interpretation space and connect it with the actors.

This example shows that the reconstruction of past events by means of video is a physical communicative activity that requires a series of small performative methods for understanding and 'making comprehensible' the visual information here on stage, quite similar to what has already been discussed in the literature on the interpretation of data sessions as re-enactments (Tutt and Hindmarsh 2011; Meyer and Meier zu Verl 2013; Reichertz 2013). These methods are not limited to a mere replay of individual gestures, but are integrated into the communicative construction of evidence. It refers to the sequence that can be precisely located in time and space, which I have already referred to here as a narrative. The viewer is not simply shown the events to be seen, but events are made communicatively visible step by step: they are demonstrated.

So far, I have shown that this demonstration takes place, on one hand, through the identification and visualization of narrative-relevant actors and on the other, through their visualization using postures and gestures in space. This location in space is further developed in the lecture by Joscha and Otto. Joscha then explains his suspicions about the motive of the policemen, or rather: he suggests that on the basis of the prehistory of the event, namely the inquiring and writing down by the cyclist, there is a plausible motive of the policemen for their action against the cyclist, because this cyclist had taken notes and asked for the service number, he was seen by the policemen - and this is here to a certain degree speculation - either as a troublemaker or threat. This interpretation is then based on a reconstruction of the course of crime, in which the movements in space, pointing gestures and glances of the police officers at each other are interpreted as evidence of a planned action.

The arguments leading to this interpretation that had already begun before are finally taken up again. Thus Otto, after the two have discussed some other points and have advanced the video further up to the actual core event, shows an important detail at a very prominent place. The still image of the scene had already circulated as the concise key image on the internet and in media. Otto is less concerned here with the already familiar, but very clearly visible blows of the policeman in front of the picture, but rather with the fine gestures of the riot control units' leader, turning towards them and then looking away. Otto clearly emphasizes his actions and presents them as evidence for the previous thesis.

Fragment D4,Worbereitung der Aktion 2"; Timecode 20:04-20:45)
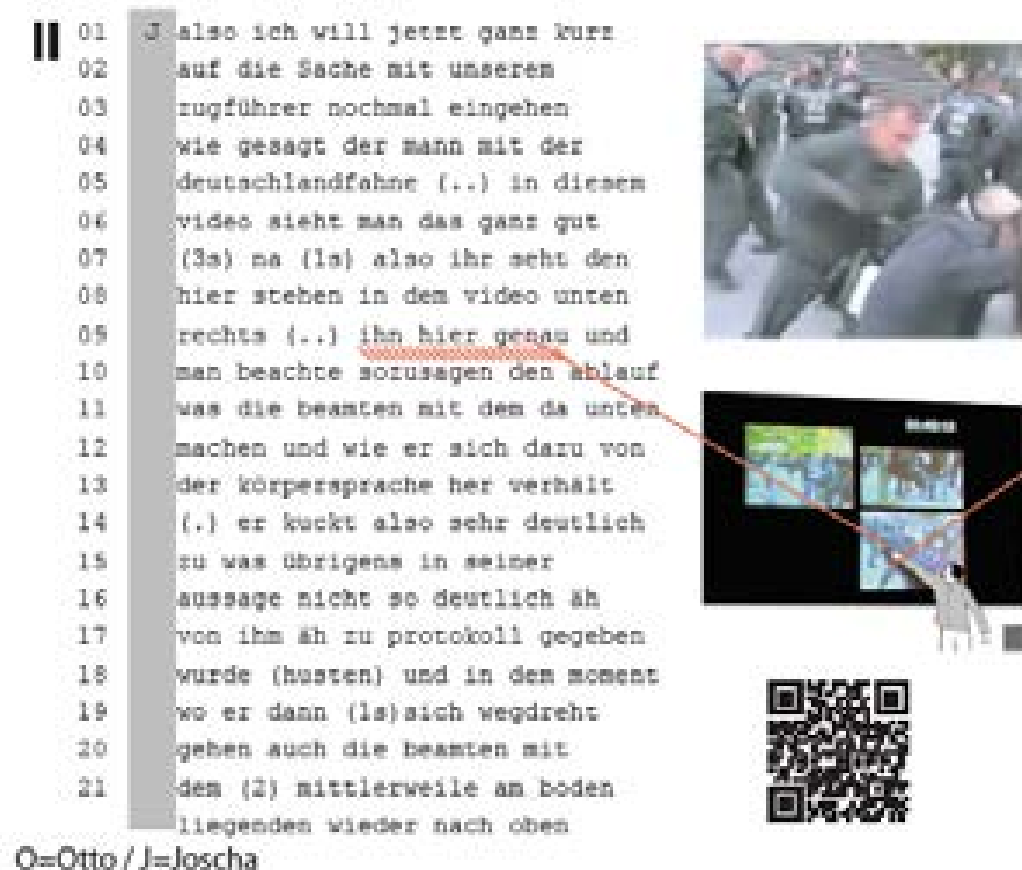
1 vant to go into the sacter gont to go ine very brielly again as said the nan With the gernat bag ....)

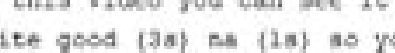
ore his geanding here in the udeo down righe to in the bisecty here and now poot bis oxecty hers and now
please pay attention to this

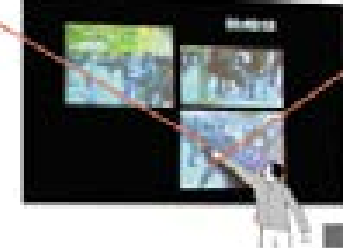
pogerure how the c1vil servane, 16 deal with hin down there and how he behaves towards that

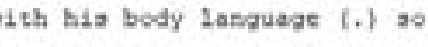
the observes is very elesriyl, that 15 sor clearly part of his statement that was protocolled
(eough) and in the exast momens $\mathrm{O}=\mathrm{Otto} / \mathrm{J}=$ Josch Vhere he then (19) tarns axay
Also the oscials vith the guy iz) now lying on the ground csace up again

This interpretation of the video is therefore not only about a pure typification of individual actions, but about detailed demonstration, intended to clarify a more complex argument, namely that the use of force against the cyclist, in this case, was not only a singular assault of an individual policeman, but the result of a coordinated agreement within the unit. In order to be able to put forward this argument, indications of a longer, embedded reconstruction of the event are systematically related to each other, then finally condensed into evidence by the finely coordinated emphasis of the police leader's body movement (which could be substantiated as a random one, without the embedding).

The interpretation of the video is thus an exemplary case for a common commu- 
nicatively constructing trace-seeking and contextualizing evaluation. However, it is not subject to the strict requirements of evidence in a court case, since it was 'only' presented at a conference and can thus at most have an indirect effect or a mass media effect. This is a single case of an analysis carried out with great effort and availability of a great deal of video material, which goes beyond the limits of the activities of everyday video analysis in police units. In principle, however, the procedure is comparable, as it also ranges from a procurement, selection of videos, context description, the search for relevant, categorizable actions, the synopsis of different perspectives to the plausibilisation of the evidence of actions of concrete actors and underlying patterns (which can be understood as command structure here).

\section{SUMMARY OF RESULTS}

The reconstruction of interpretive work with video data by police (or in my example the counter analysis taking up the practices) is an established practice within the framework of organization. The carrying out of such tasks typical for the field of policework. It consists of routine tasks of the police officers, who routinely cut out key events in the recordings for the communication of visual identification features or for documentation purposes, highlighting the course of criminal acts, by means of still images and hand over the video data in edited form to some clerks and finally to courts. This course of interrelated activities can also be described as work arc. As shown, communicative explanations are given at each 'transfer point' to make the data material speak and to make the analysis appear plausible. The video analyses are thus embedded in the work of the police via the organisational structure and the typical activities of the field.

The analysts develop a very special view of the video material, by restricting it to the existing recordings and at the same time allowing them to be viewed as often as they like, slowed down, etc. This view is expressed in their practical handling of video materials. Goodwin (1994) described this view with the concept of Professional Vision: An object of knowledge is created within the framework of specific activity ${ }^{15}$ in which professional actors involved relate a series of discursive practices to a visua field (domain of scrutiny). The establishment of this relation is, as the terms suggest, a practical-communicative activity. Typical discursive elements, such as coding schemes, emphasis or the use of material representations are central components of visual practices shared by professionals.

Police officers use special knowledge, typical of their profession, which is codified

${ }^{15}$ The term activity describes the systematic, longer context of action typical for the respective field, in which discursive practices are integrated. The concept of activity, which is very similar to that of George Herbert Mead's "social act", plays a role above all within the framework of the theory of ac tivity (cf. Engeström, Miettinen., and Punamäki 1999), which was developed on the basis of the Marxis cultural-historical psychology of Vygotsky and Leontiev (among others). Conceptually, the activity can concept of work at Strauss. in different categories of typical criminal acts and more precise definitions of them The shared, standardised sign system and the resulting archive of individual observations serve to establish a joint observation project, by means of which a number of perpetrators are to be identified over a longer period of time and from which evidence can be quickly extracted.

However, this is only one part of the activity, because each individual case consists of the linking of a series of different individual proofs, to a comprehensible trace. The activity of assembling consists of the linking of existing objectifications of human action to a convincing and clearly communicable overall reconstruction of a course of action. This activity constitutes the search for traces. It is important to emphasise that this is not usually a solitary exercise, but that teams collect the various pieces of evidence and coordinate their activities, in line with the joint work project - the organised work arc. Using the example of counter-analyses, I have presented less about this organizational perspective, but rather the local, situational reconstruction of the event as a physically communicative activity of emphasizing, clarifying and embedding it in the context of precisely such a track, for which the concept of narration of fers itself here (because a story is really being told). The reconstruction, in this field, the search for traces, thus takes place situatively, but the actors always refer in their organized activities to future steps and goals that are linked to the specific characteristics of the field.

\section{CONCLUSION ON COMMUNICATIVECONSTRUCTION}

The special focus of this empirical case study relies not only on the empirical record ing of the empirical phenomenon (i.e. the video work in police work), but also on theoretical embedding of the research design in the study itself. The strength of communicative constructivism relies on placing the phenomena, that are often the focus of interest in studies of social situations, the individual courses of action and sequences, the bodies and objects and the practices, forms and communicative genres, that can be identified from them in a broader context. Through the processes of institutionalizing work activities (here the formation of work sheets), the establishment of new knowledge based on concrete actions and communicative work practices by self-establish experts, organizations are founded, and fields are established. Material objectivations also ensure durability but must be constantly reinterpreted. This view guides the study to enable more precise, processual understanding of the communicative processes of the communicative construction of reality. Thus, my study is not only designed to learn something about an esoteric special field of knowledge - the world of video an alysts - but it is more comprehensively about an understanding of the communicative processes of interpreting audiovisual data in general. Showing and interpreting are as I have explained - communicative actions, where interpretation is much more than purely cognitive process of individuals. Furthermore, my study is reflexive because it deals with the communicative interpretation of videos, i.e. what I have done myself for research purposes. A more precise, in a narrow sense, reflexive empirical investigation of social science methods, is still in its infancy, but my work on "Vernacular Video 
Analyses" is a foil with which other sociological video analyses can be contrasted.

FUNDING: This research received no external funding.

CONFLICTS OF INTEREST: The author declares no conflict of interest.

ACKNOWLEDGEMENTS: I would like to thank the editors of this volume and the reviewers for their very insight and helpful comments. I also like to thank Frederike Brandt for her help with the references and comments.

\section{REFERENCES}

Auslander, Philip. 1999. Liveness: Performance in a Mediatized Culture: Performance in an Mediatized Culture. London etc.: Routledge.

Ball, Kirstie, Kevin Haggerty, and David Lyon. 2014. Routledge Handbook of Surveillance Studies. London etc.: Routledge.

Berger, Peter and Thomas Lukmann. 1966. The Social Construction of Reality. New York: Free Press.

Behr, Rafael. 2006. Polizeikultur: Routinen - Rituale - Reflexionen. Bausteine zu einer Theorie der Praxis der Polizei. Wiesbaden: Springer VS.

Clages, Horst and Wolfgang Steinke. 2002. Der rote Faden. Grundsätze der Kriminalpraxis. Heidelberg: Kriminalistik Verlag.

Daston, Lorraine and Peter Galison. 2010. Objectivity. New York; Cambridge, Mass.: Zone Books.

Engeström, Yrjö, Reijo Miettinen, and Raija-Leena Punamäki, 1999. Perspectives on Activity Theory. Cambridge: Cambridge University Press.

Fay, Stephen J. 1998. “Tough on crime, tough on civil liberties: some negative aspects of Britain's wholesale adoption of CCTV surveillancee during the 1990s." International Review of Law, Computers and Technology 12(2): 315-47.

Foucault, Michel. 1977. Überwachen und Strafen: Die Geburt des Gefängnisses. Frankfurt am Main: Suhrkamp Verlag.

Gates, Kelly. 2013. "The cultural labor of surveillance: video forensics, computational objectivity, and the production of visual evidence.” Social Semiotics 23(2): 24260.

Gerson, Elihu M. 1983. “Work and Going Concerns: Some Implications of Hughes” Work.” at “Theoretical Implications of E.C. Hughes' work” lecture at the meeting of the Pacific Sociological Association, San Jose.

Ginzburg, Carlo. 2011. Spurensicherung. Berlin: Verlag Klaus Wagenbach.

Goodwin, Charles. 1994. "Professional vision.” American anthropologist 96(3): 606-33.

Goodwin, Charles and Majore Harness Goodwin. 1997. "Contested vision: The discursive constitution of Rodney King.” Pp. 292-316 in Gunarsson, Louise, Per Linell, and Bengt Nordberg, ed. The construction of professional discourse. New York: Longman.

Heath, Christian and Paul Luff. 2000. Technology in Action. Cambridge: Cambridge University Press.
Heath, Christian, Marcus S. Svensson, Jon Hindmarsh, Paul Luff, and Dirk vom Lehn. 2002. "Configuring Awareness.” Computer Supported Cooperative Work (CSCW). 11(3-4): 317-47.

Hempel, Leon and Jörg Metelmann. 2005. Bild - Raum - Kontrolle: Videoüberwachung als Zeichen gesellschaftlichen Wandels. Frankfurt am Main: Suhrkamp Verlag.

Kammerer, Dietmar. 2008a. Bilder der Überwachung. Frankfurt am Main: Suhrkamp Verlag.

------. 2008b. “Die Anfänge von Videoüberwachung in Deutschland.” Kriminologisches Journal 40(4): 257-68.

Keller, Reiner, Hubert Knoblauch, and Jo Reichertz. 2013. Kommunikativer Konstrukti vismus. Wiesbaden: Springer VS.

Knoblauch, Hubert. 2008. PowerPoint, Communication, and the Knowledge Society. Cambridge: Cambridge University Press.

Knoblauch, Hubert. 2019a. "The Communicative Turn in German Sociology of Knowledge.” Society Register 3(1): 23-38. DOI: 10.14746/sr.2019.3.1.02

-----. 2019b. The Communicative Construction of Reality. Taylor and Francis: New York. Knoblauch, Hubert, Bernt Schnettler, and René Tuma. 2014. Videography. Introduction to Interpretive Videoanalysis of Social Situations. New York etc.: Peter Lang.

Krämer, Sybille, Werner Kogge, and Gernot Grube, ed. 2007. Spur: Spurenlesen als Orientierungstechnik und Wissenskunst Originalausgabe. Frankfurt am Main: Suhrkamp Verlag.

Latour, Bruno. 1999. Pandora's Hope: Essays on the Reality of Science Studies. Cambridge, Mass: Harvard University Press.

Laurier, Erik, Ignaz Strebel, and Brown, Barry .2008. "Video Analysis: Lessons from Professional Video Editing Practice.” Forum: Qualitative Social Research 9(3).

Lucht, Petra, Lisa-Marian Schmidt, and René Tuma. 2013. Visuelles Wissen und Bilder des Sozialen. Wiesbaden: Springer VS.

Luff, Paul, Christian Heath, and Marcus S. Svensson. 2008. "Discriminating Conduct: Deploying Systems to Support Awareness in Organizations." International Journal of Human-Computer Interaction 24(4): 410-36.

Luhmann, Niklas. 1997. Die Gesellschaft der Gesellschaft. Frankfurt am Main: Suhrkamp. Lyon, David. 2007. Surveillance Studies: An Overview. Cambridge etc.: Polity Press.

Mair, Michael, Chris Elsey, Paula V. Smith, and Patrick G. Watson. 2018. "War on video: Combat footage, vernacular video analysis and military culture from within." Ethnographic Studies 15: 83-105.

Messner, Daniel. 2013. "Klassifizieren und archivieren. Die Anfänge biometrischer Identifizierungstechniken. ” Das Archiv. Magazin für Kommunikationsgeschichte 3: $114-21$.

Messner, Daniel, Stephen Gruber, and Christoph Musik. 2012. “Personen identifizieren - Eine Geschichte von Störfallen Identifiying persons - A history of incidents Kommentar zu Raul Gschrey." Kriminologisches Journal 3: 219-24.

Meyer, Christian and Christian Meier zu Verl. 2013. "Hermeneutische Praxis. Eine ethnomethodologische Rekonstruktion sozialwissenschaftlichen Sinnrekonstruierens." Sozialer Sinn 14 (2): 207-34. 
Mitchell, William J. T. 2002 “Showing Seeing: A Critique of Visual Culture”, Journal of Visual Culture 1(2):165-81.

-----. 2005. What Do Pictures Want?: The Lives and Loves of Images. Chicago: University of Chicago Press.

Norris, Clive and Gary Armstrong. 1999. The maximum surveillance society: the rise of CCTV. Oxford; New York: Berg.

Perry, Mark, Oskar Juhlin, and Arvid Engström. 2014. “Dealing with Time, Just In Time: Sense-Making and Clip Allocation in Multiperson, Multistream, Live Replay TV

Production.” Pp. 262-86 in Broth, Mathias, Eric Laurier, and Lorenza Mondada, ed. Studies of video practices: video at work. New York: Routledge.

Reichertz, Jo. 1991. Aufklärungsarbeit. Stuttgart: Lucius and Lucius.

-----. 1996. “Spurenlesen oder Konstruktion?” Pp. 12-29 in Reichertz, Jo and Norbert Schröer, ed. Qualitäten polizeilichen Handelns. Wiesbaden: Springer VS.

-----. 2003. Hermeneutische Polizeiforschung. Opladen: Springer VS.

-----. 2007. "Die Spur des Fahnders. Wie Polizisten Spuren finden. ” Pp. 309-32 in Krämer, Sybille, Werner Kogge, and Gernot Grube, ed. 2007. Spur: Spurenlesen als Orientierungstechnik und Wissenskunst Originalausgabe. Frankfurt am Main: Suhrkamp Verlag.

---. 2009. Kommunikationsmacht. Wiesbaden: Springer VS

-----. 2013. Gemeinsam interpretieren. Wiesbaden: Springer VS.

Reichertz, Jo and Carina Englert. 2011. Einführung in die qualitative Videoanalyse. Wiesbaden: Springer VS.

Schutz, Alfred. 1962: The Problem of Social Reality: Collected Papers I. The Hague: Martinus Nijhoff.

Schmidt, Robert and Wiesse, Basil. 2019. "Online-Teilnehmer*innenvideo - ein neue Datentyp für die interpretative Sozialforschung? ” Forum: Qualitative Social Research. 20(2).

Schröer, Norbert. 1996. Qualitäten polizeilichen Handelns - Beiträge zu einer verstehenden Polizeiforschung. Opladen: Westdeutscher Verlag.

Schwartz, Louis-Georges. 2009. Mechanical Witness: A History of Motion Picture Evidence in U.S. Courts. Oxford etc.: Oxford University Press.

Strübing, Jörg. 2005. Pragmatistische Wissenschafts- und Technikforschung: Theorie und Methode. Frankfurt am Main: Campus Verlag.

Tagg, John. 1988. The Burden of Representation: Essays on Photographies and Histories. Minneapolis: University of Minnesota Press.

Tomasello, Michael. 2010. Origins of Human Communication. Cambridge, MA: The MIT Press

Tuma, René. 2017. Videoprofis im Alltag - Die kommunikative Vielfalt der Videoanalyse. Wiesbaden: Springer VS.

Tutt, Dylan and Hindmarsh, Jon. 2011. "Reenactments at work: Demonstrating conduct in data sessions" Research on Language \& Social Interaction 44: 211-236.

Ullrich, Peter and Gina R. Wollinger. 2011. "Videoüberwachung von Versammlungen und Demonstrationen - Blick auf ein verwaistes Forschungsfeld.” Pp. 138-56 in Zurawski, Nils, ed. Überwachungspraxen - Praktiken der Überwachung: Analysen zum Verhältnis von Alltag, Technik und Kontrolle. Opladen: Budrich.

Weizmann, Eyal, Susan Schuppli, Shela Sheikh, Anselm Franke, Thomas Keenan, and Paulo Tavares. 2014. Forensis: The Architecture of Public Truth. Berlin: Sternberg Press.

Wilson, Christopher P. 2000. Cop Knowledge: Police Power and Cultural Narrative in Twentieth-Century America. Chicago: University of Chicago Press.

Wilson, Dean and Tanya Serisier. 2010. "Video activism and the ambiguities of countersurveillance.” Surveillance \& Society 8 (2): 166-80.

Zielinski, Siegfried. 2010. Zur Geschichte des Videorecorders. Potsdam: Polzer.

Zurawski, Nils, ed. 2007. Surveillance Studies: Perspektiven eines Forschungsfeldes. Opladen: Budrich.

\section{BIOGRAPHICAL NOTE}

René Tuma is research and teaching assistant in sociology at the Technical University of Berlin, Germany.

OPEN ACCESS: This article is distributed under the terms of the Creative Commons Attribution Noncommercial License (CC BY-NC 4.0) which permits any noncommercial use, and reproduction in any medium, provided the original author(s) and source are credited. 
